\title{
Differentiation of Bone Marrow-Derived Mesenchymal Stem Cells into Neuron-Like Cells Affected by Extract of Ginger Officinale
}

Mohammad Jabbarian', ${ }^{1,}$ Marzieh Darvishi' ${ }^{2,}$, Parastoo Barati Dowom², Azam Babakhani', Ali Jahanbazi JahnAbad $^{2}$, Kambiz Roshanaei ${ }^{*}$

\author{
${ }^{1}$ Department of Physiology, Faculty of Sciences, Qom Branch, Islamic Azad University, Qom, Iran \\ ${ }^{2}$ Shefa Neuroscience Research Center, Khatam Alanbia Hospital, Tehran, Iran \\ ${ }^{3}$ Department of Anatomy, Faculty of Medicine, Ilam University of Medical Sciences, Ilam, Iran
}

\begin{tabular}{lll} 
& Article Info: & \\
\hline Received: 3 Apr 2016 & Revised: 1 Oct 2016 & Accepted: 28 Jan 2017
\end{tabular}

\section{A BSTRACT}

Introduction: Ginger (Zingiber officinale) is an herbal medicine that has been used for treatment of many disorders. Ginger have been identified for antioxidant activity and neuroprotective effects. Ginger can alleviate cell death and regenerate the motor function in rats with spinal cord injury. In the present study, we investigated the effect of ginger on neural induction of bone marrow-derived mesenchymal stem cells and their differentiation into neural cells. Materials and Methods: Bone marrow stromal cells (BMSCs) were isolated from the femurs and tibias of rat and these cells were induced with the appropriate dose of ginger extract. These cells were assessed by crysel violet staining and immunocytochemistery.

Results: The results showed that cells isolated from bone marrow were immunoreactive to CD106 (95.67 \pm 2.26$)$, CD90 (71.52 \pm 6.64 ) but not to hematopoietic cell markers (CD45). Induced BMSCs by 10, 20, 30, 40, 50, 60 and $70 \mathrm{microg} / \mathrm{ml}$ of ginger after 12 and 24 hours were positive for nissl body. The highest percentage of live cells was observed with 30 microg/ $\mathrm{ml}$ of ginger and maximum neural-like cells was induced with $60 \mathrm{microg} / \mathrm{ml}$ ginger after 12 hours. Conclusion: Ginger can be considered as a potential alternative non-toxic substance for induction of neuronal cells and can be used for induction of BMSCs to neuron-like cells.

Key words:

1. Bone Marrow

2. Rats

3. Death

*Corresponding Author: Kambiz Roshanaei

E-mail: kambizroshanaei@gmail.com 


\section{تمايز سلولهاى بنيادى مزانشيمى مشتق از مغز استخوان به سلولهاى شبه عصبى تحت تأثير عصاره زنجبيل}

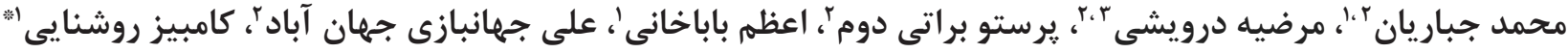

$$
\begin{aligned}
& \text { 'كروه فيزيولورى، دانشكده علوم، واحد قم، دانشكاه آزاد اسلامى، قم، ايران }
\end{aligned}
$$

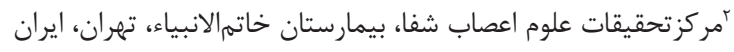

$$
\begin{aligned}
& \text { "كروه آناتومى، دانشكده يزشكى، دانشكاه علوم يزشكى ايلام، ايلام، ايران إنان }
\end{aligned}
$$



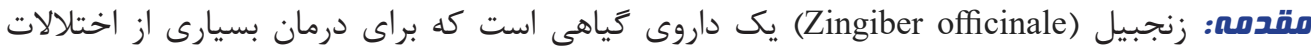

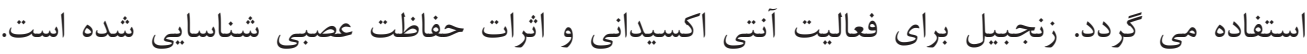

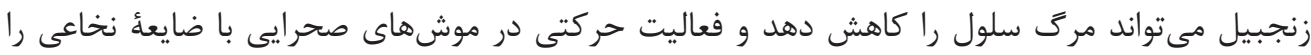

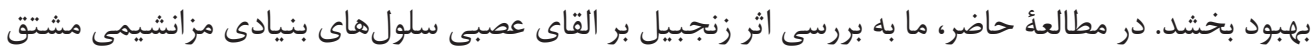

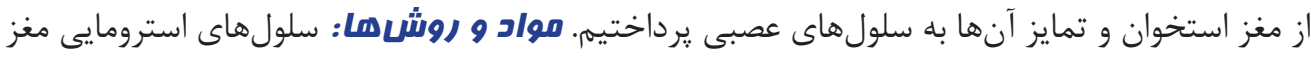

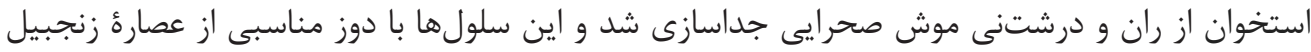

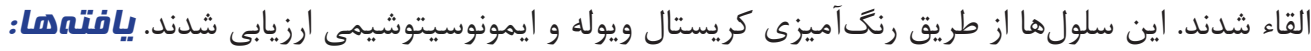

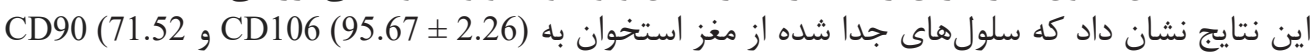

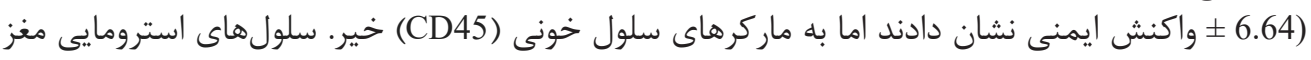

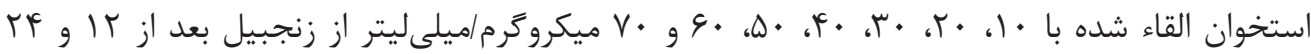

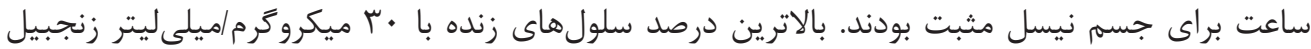

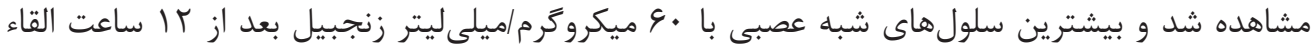

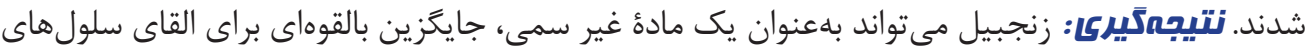

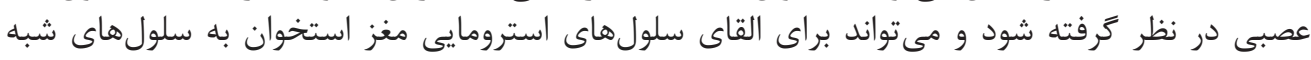

كليد وازهها:



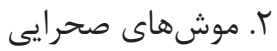

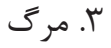

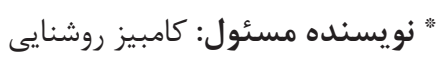
آدرس الكترونيكى: kambizroshanaei@gmail.com 


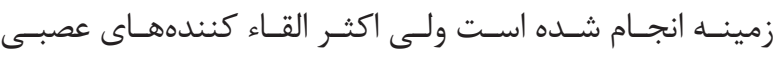

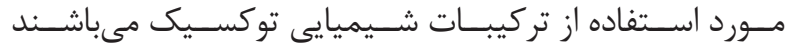

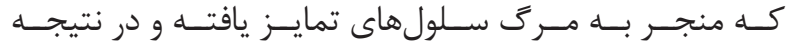

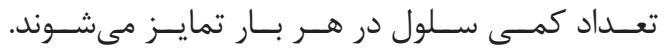

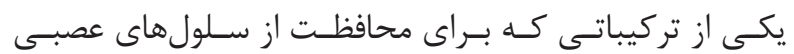

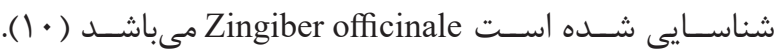

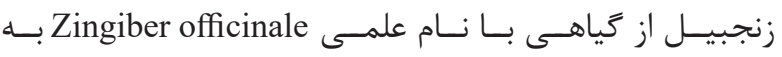



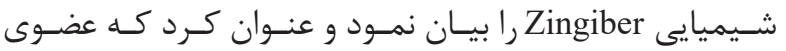

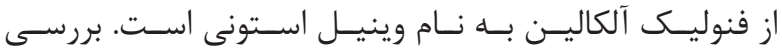

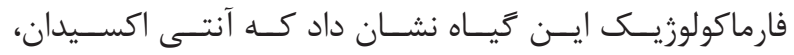

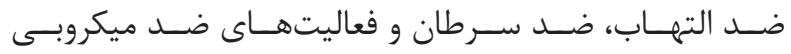
دار د د م

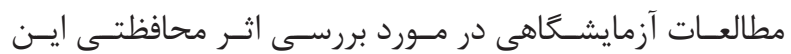

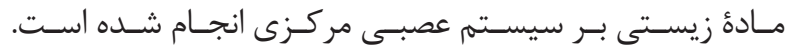

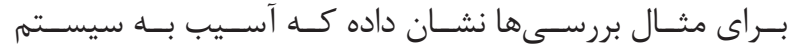

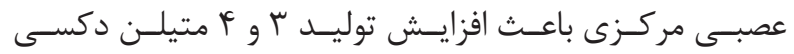

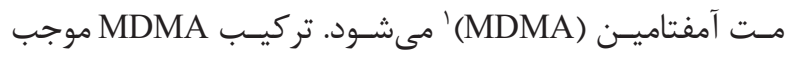

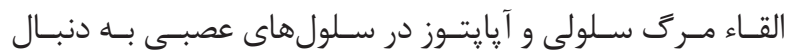

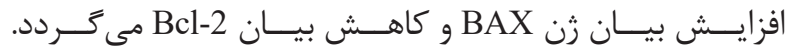

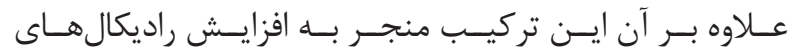

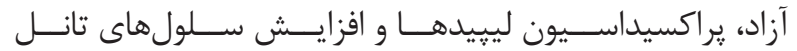

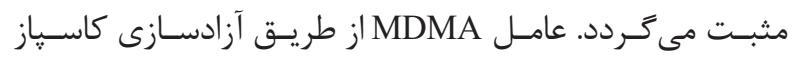

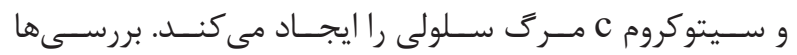

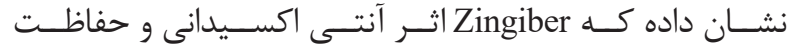

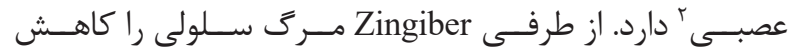

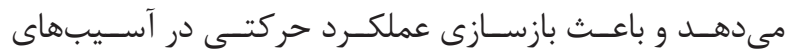

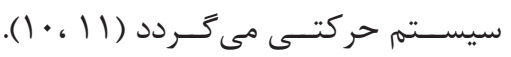

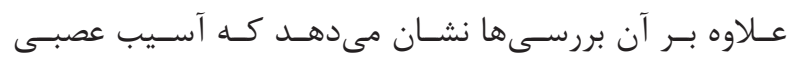

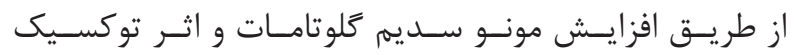

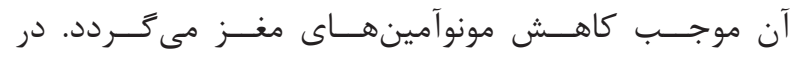

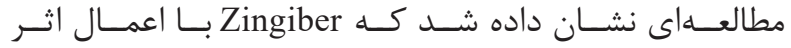

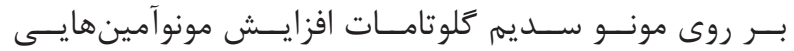

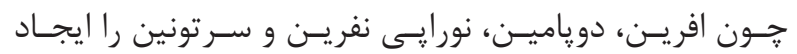

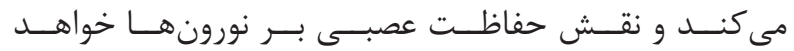

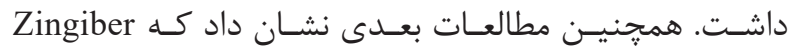

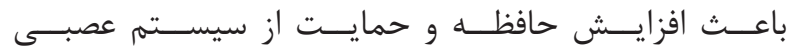

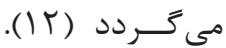

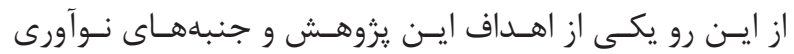





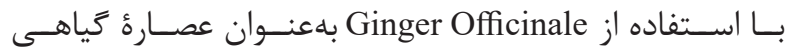

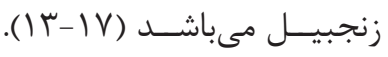

مواد و روشها

ا. جداســازى و كشــت ســلول هاى بنيــادى مشــتق از

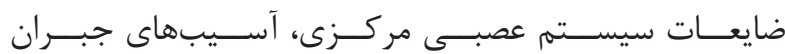

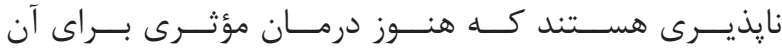

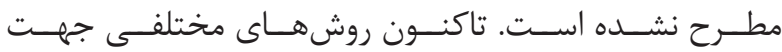

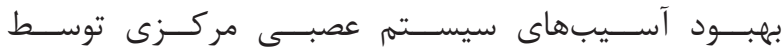

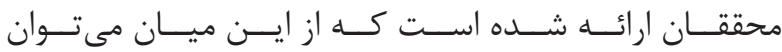

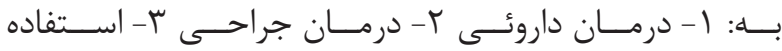

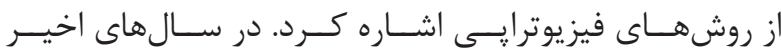

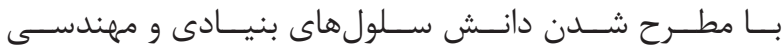

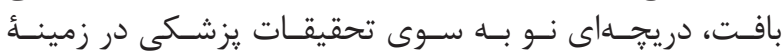

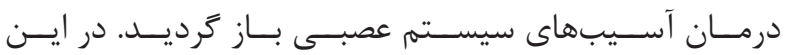

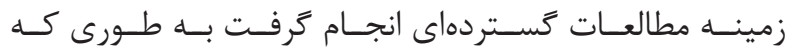

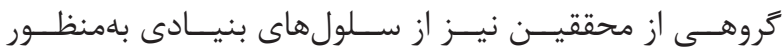

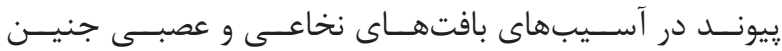

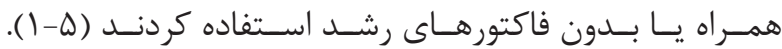
اسـتفاده از سـلولهاى بنيــادى جنينـى در ترميـم ضايعـات



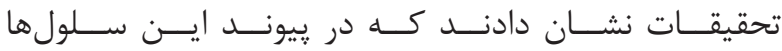

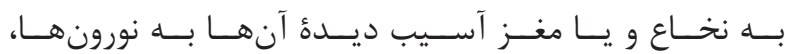

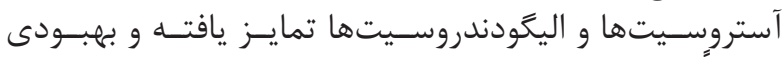

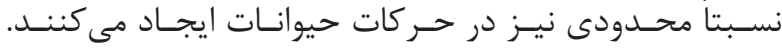

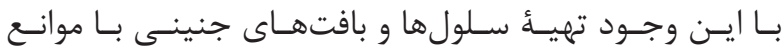



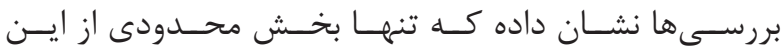

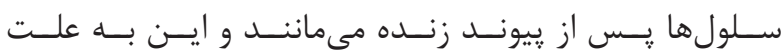

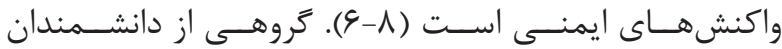

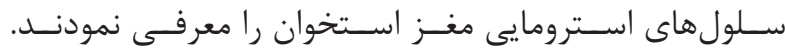

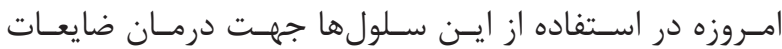



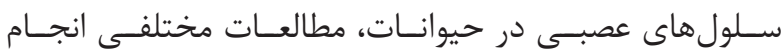

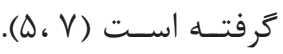



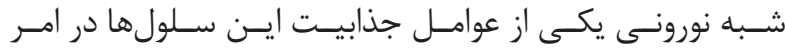

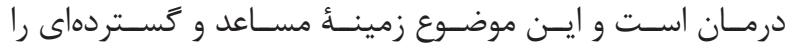

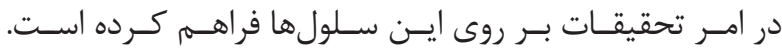

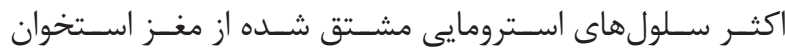

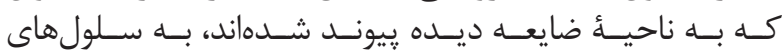

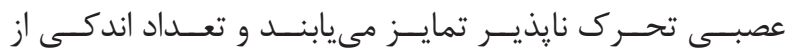

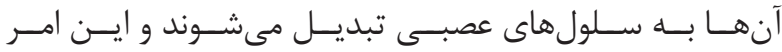

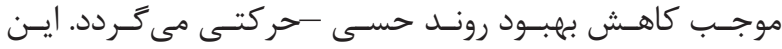

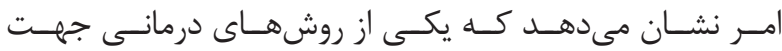

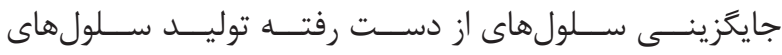



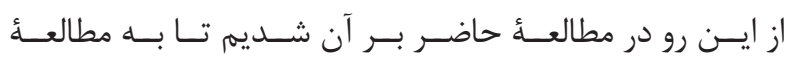

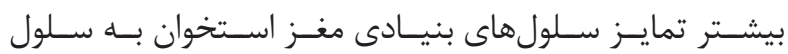

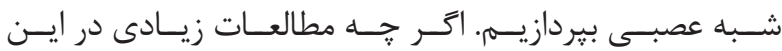




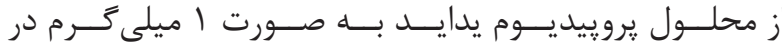

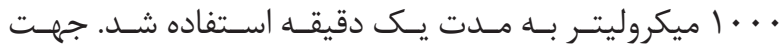

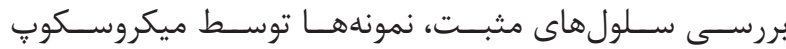

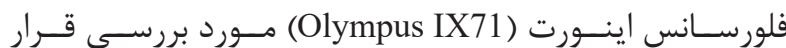
كرفتنــد.

" ا. عصارهتيرى از ريزوم زنجبيل

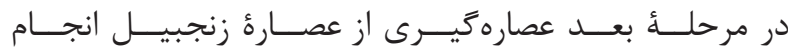

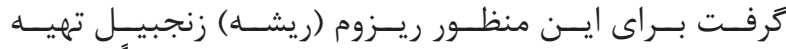

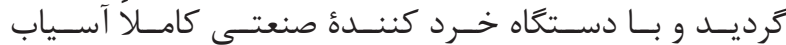

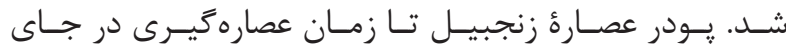

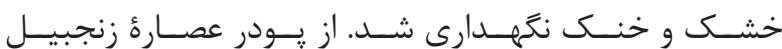

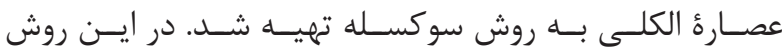

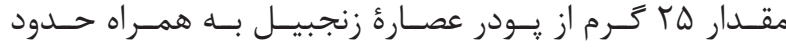

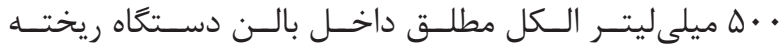

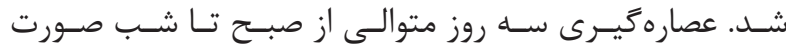

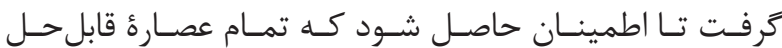

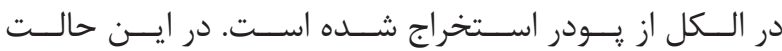

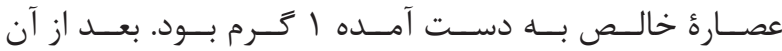

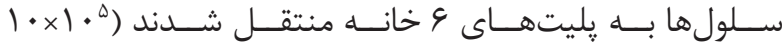

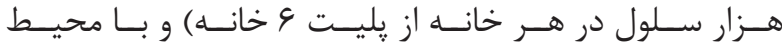

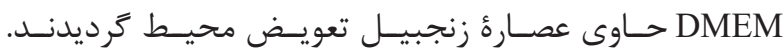

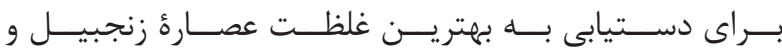

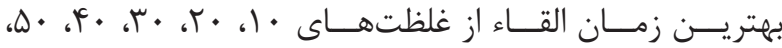

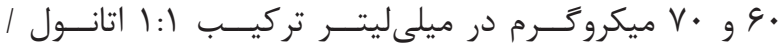
DMSO

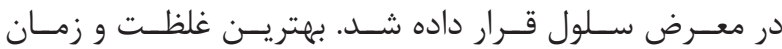

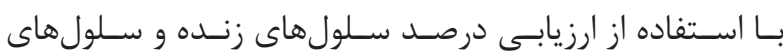

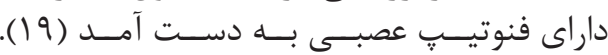
F (أ. بررسى آزمون زنده ماندن

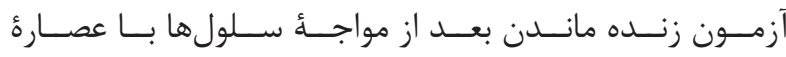

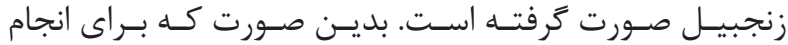

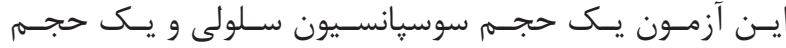

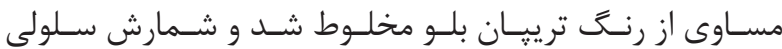

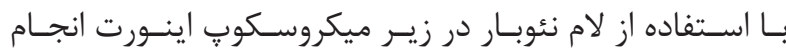



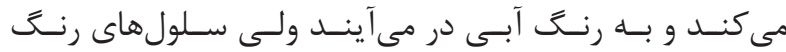

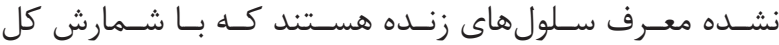



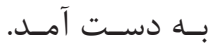

$$
\text { ه. بررسى رنََ آميزى كرزيل ويوله }
$$

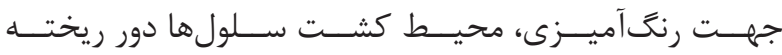

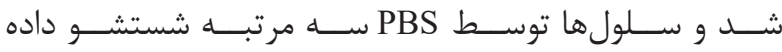

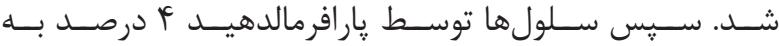

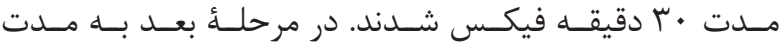

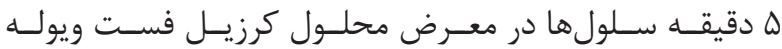

مغــز اســتخوان

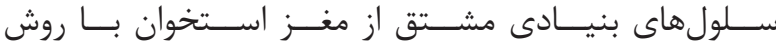

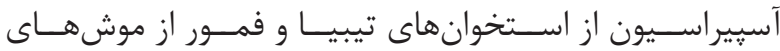



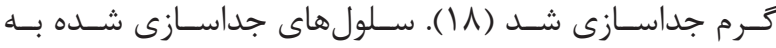

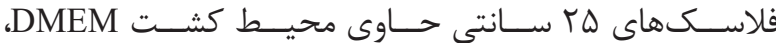

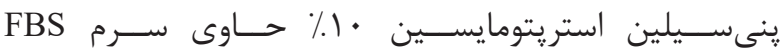

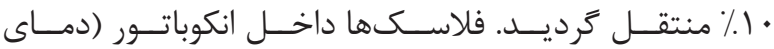

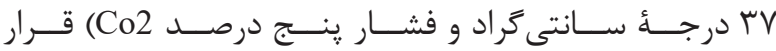

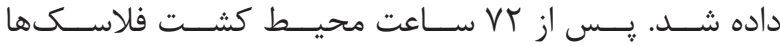

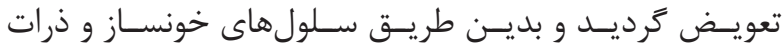

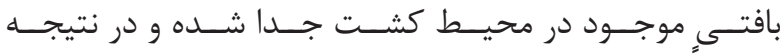

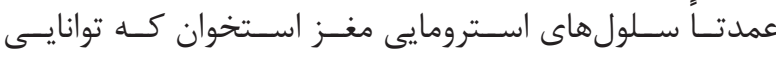

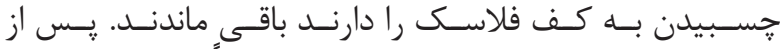

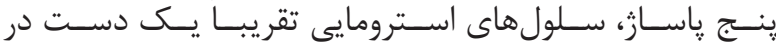

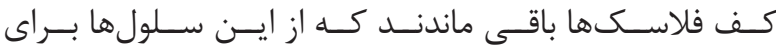

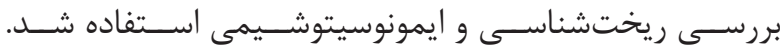

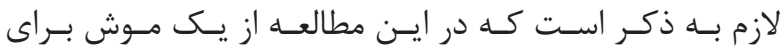

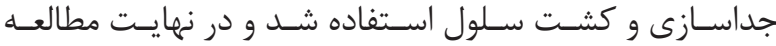

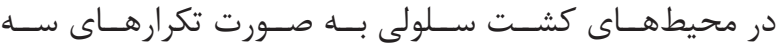

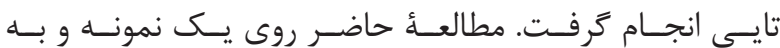

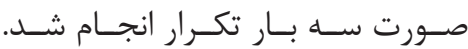

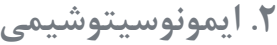

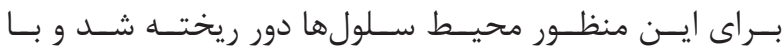

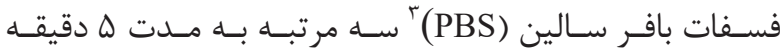

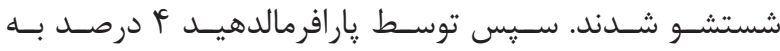

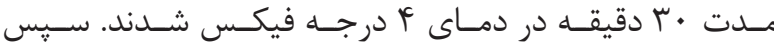

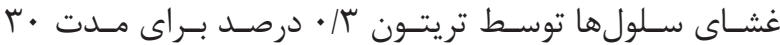



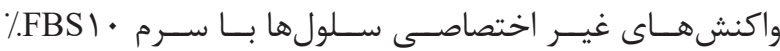

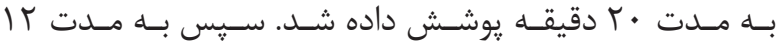

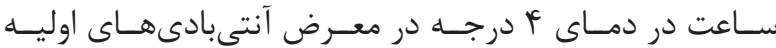

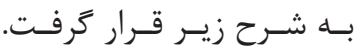

Mouse anti- CD106, polyclonal antibody 1:300(; Millipore)

Mouse anti-CD90, monoclonal antibody 1:200(; Millipore)

Mouse anti-CD45 polyclonal antibody 1:300(; Millipore )

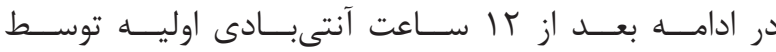

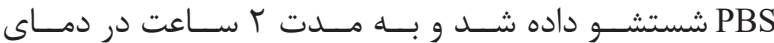

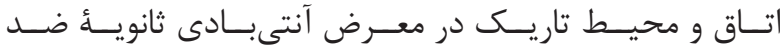

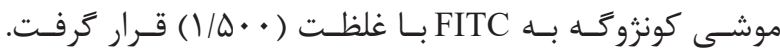

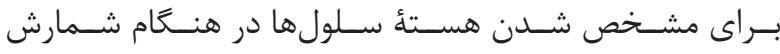




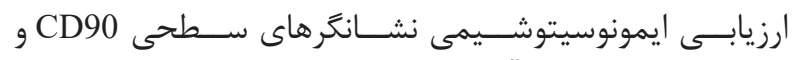



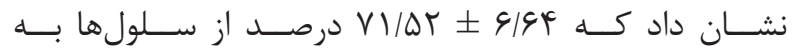



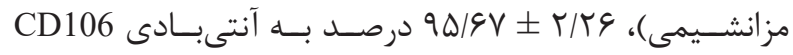

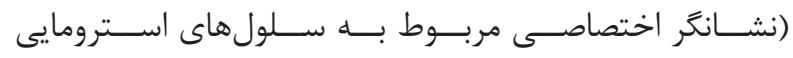

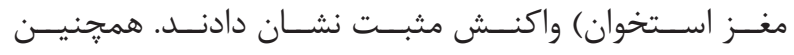

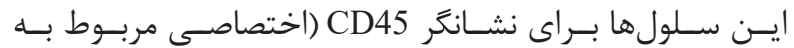



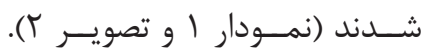
r. نتايج آزمون زنده ماندن

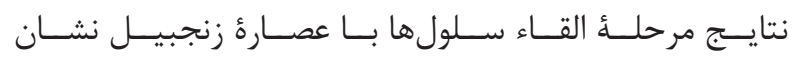

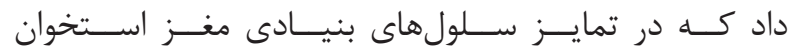

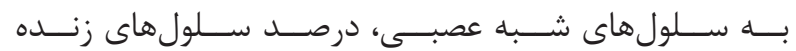

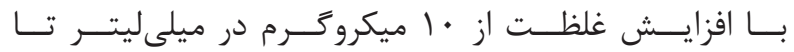

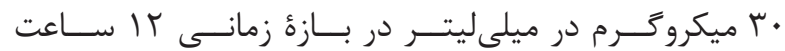

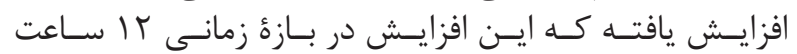

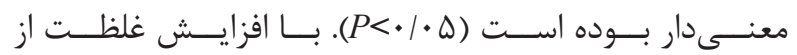

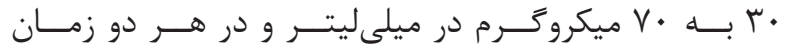



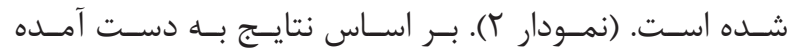

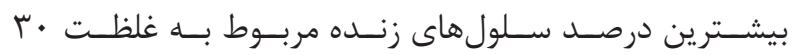



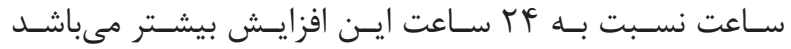

. $(P<\cdot / \cdot \Delta)$

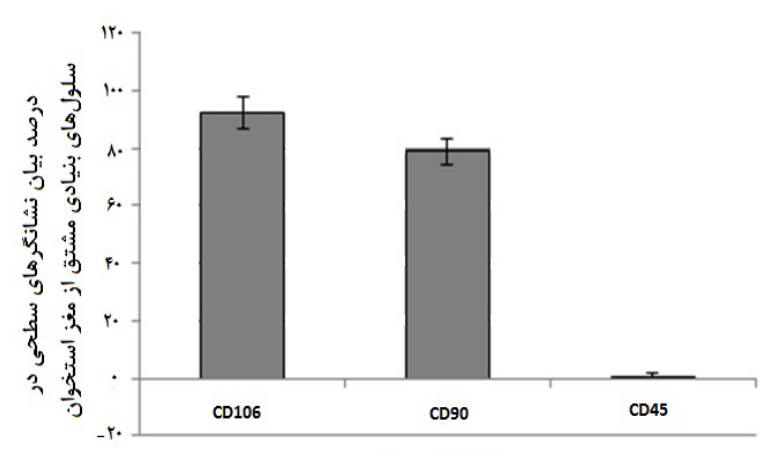

نشانكرهاى سطحى

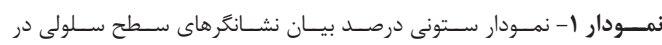

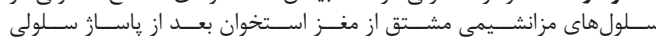

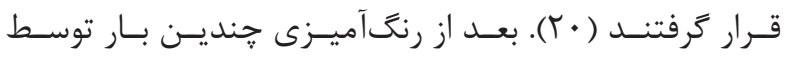

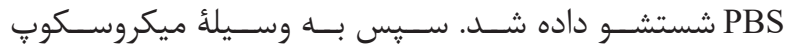

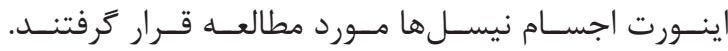

$$
\text { و. تجزيه و تحليل آمارى }
$$

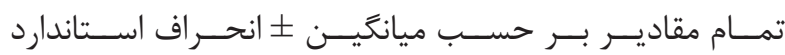

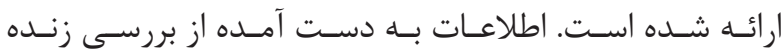



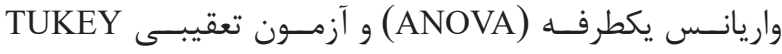

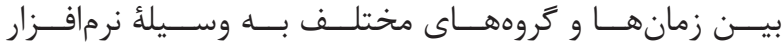

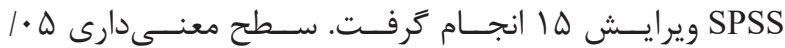

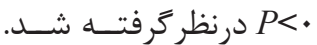

كافتهها

ا. جداســازى و كشــت ســلول هاى بنيـادى مزانشـــــى إنى مشــتق از مغز اســـتخـوان



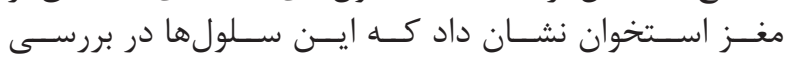

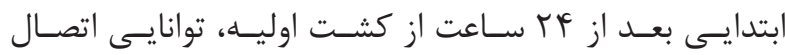

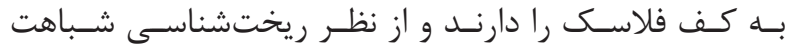

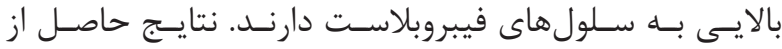

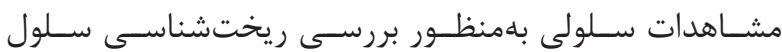

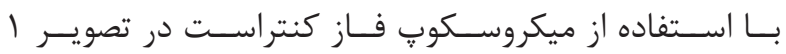

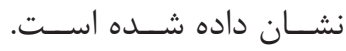
r. إبمونوسيتوشيمى

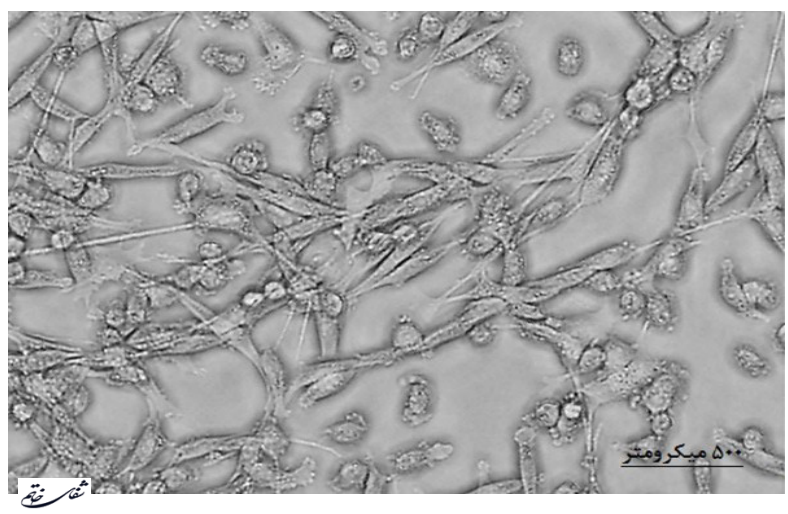

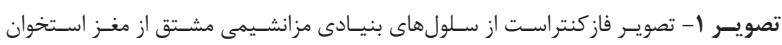



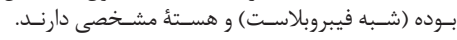


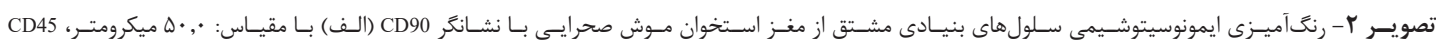

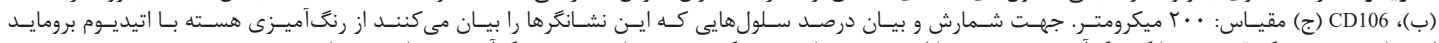

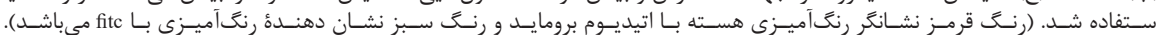




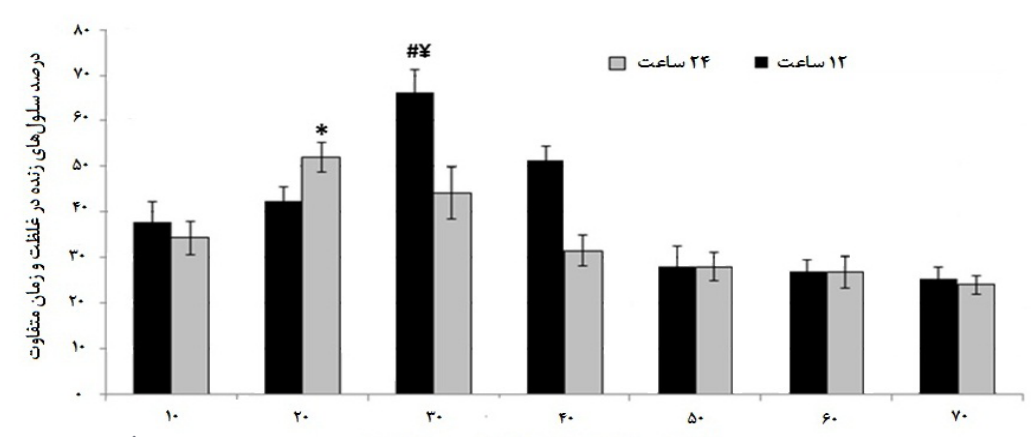

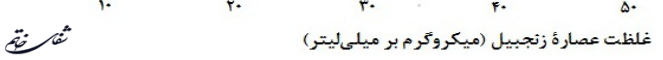

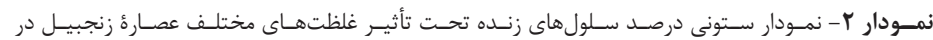

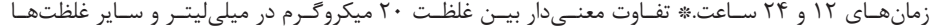

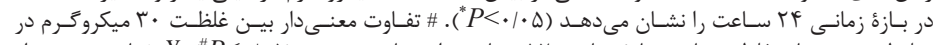



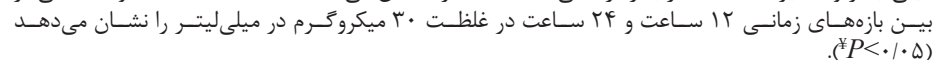

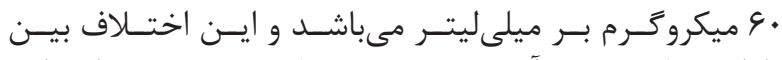

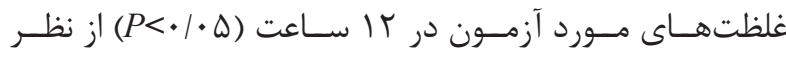

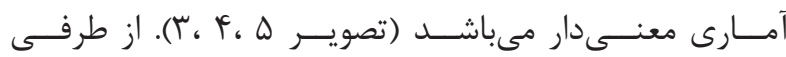

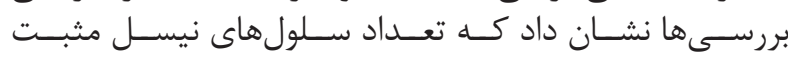

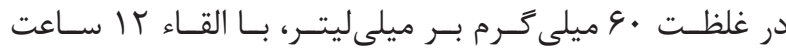

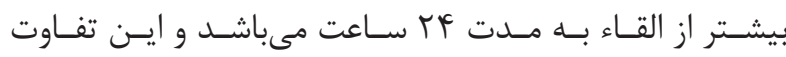
معنــى دار اسـت (نمــودار س).

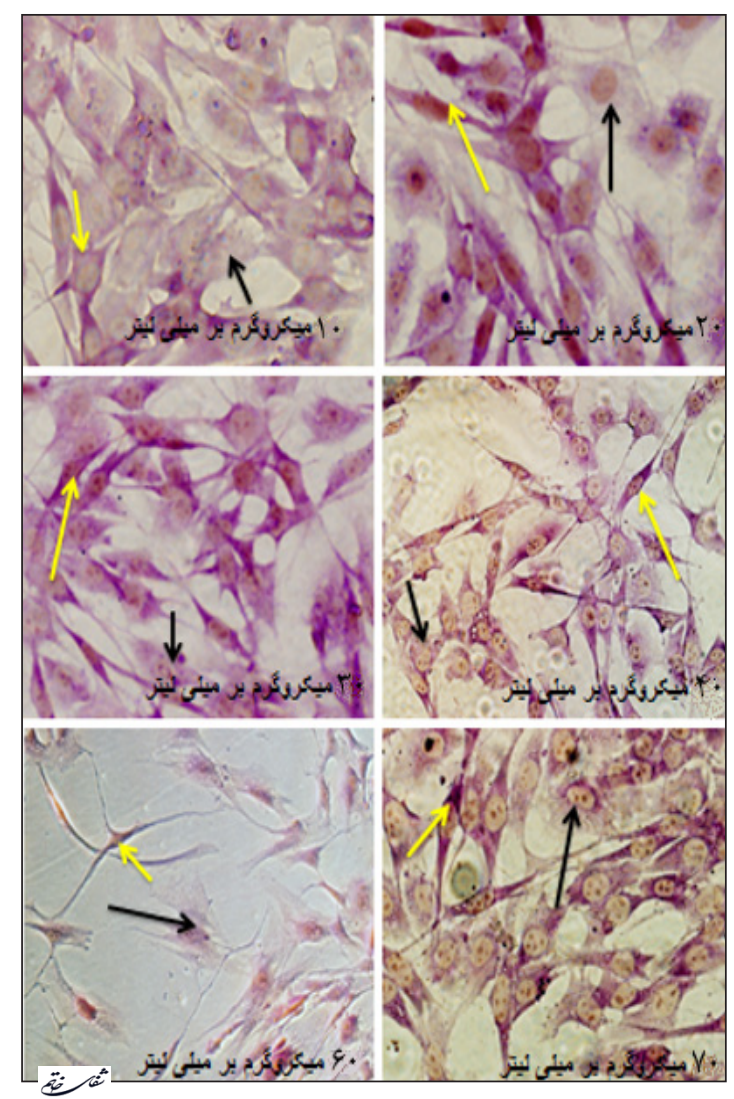

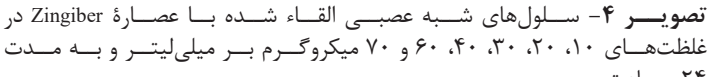



P. نتايج رنتَ آميزى كرزيل ويوله

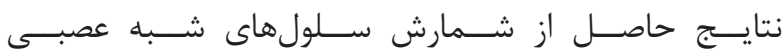

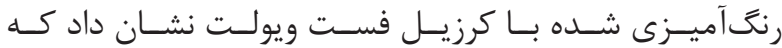

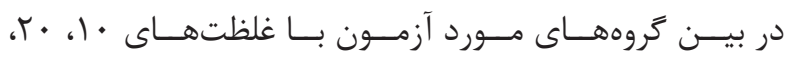

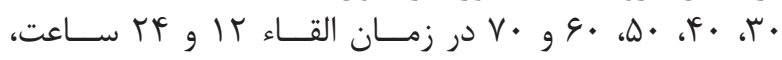



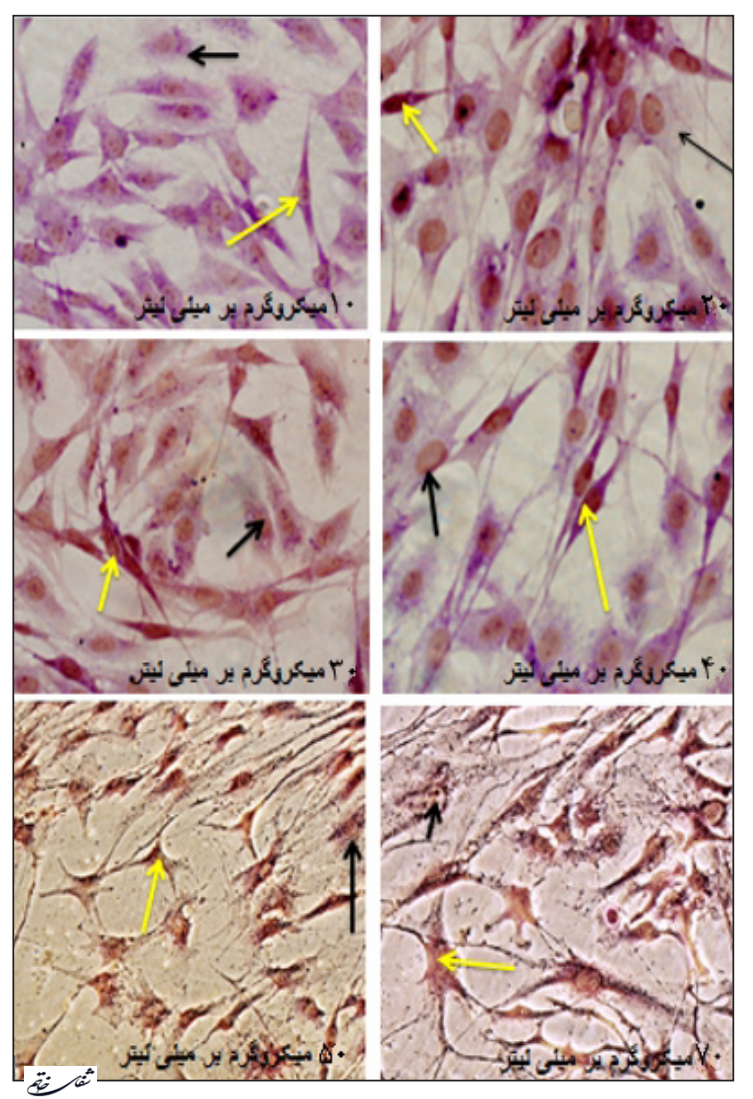

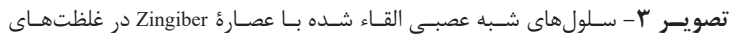

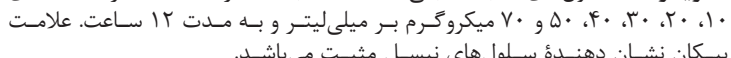




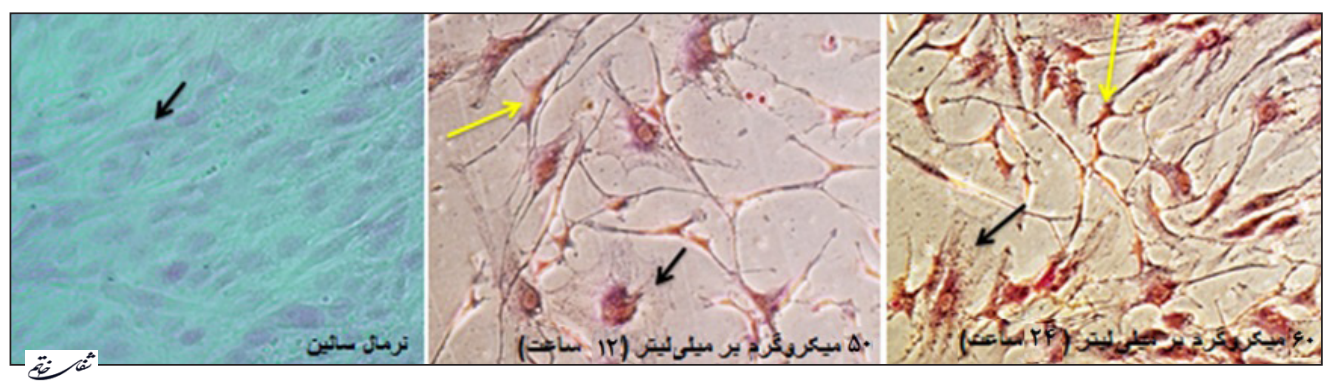

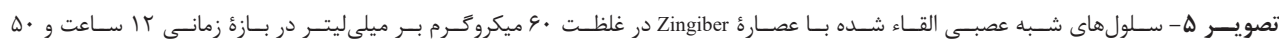

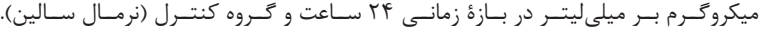
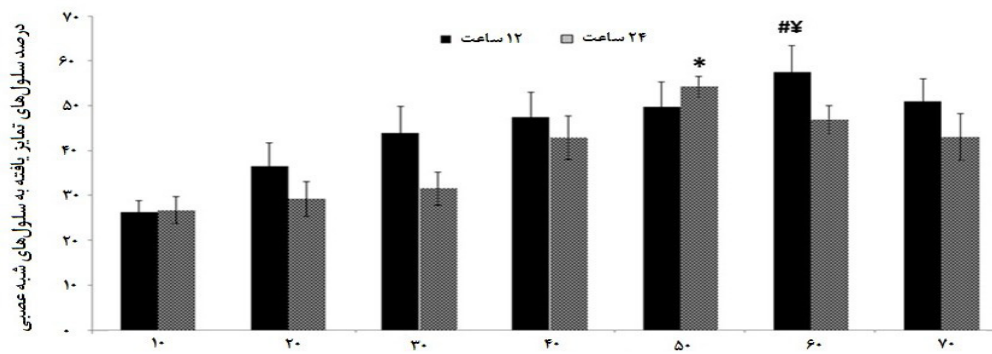

萡

غلظت عصارة رتجبيل (ميكروكرم بر ميلي،يليتر)

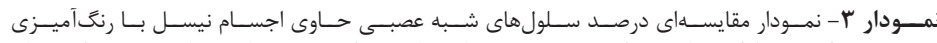

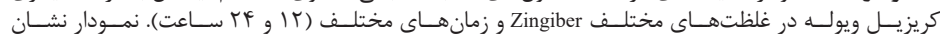

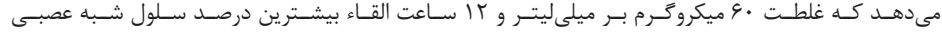

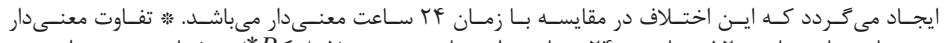

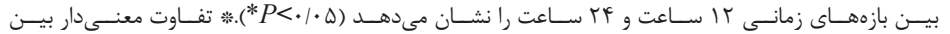

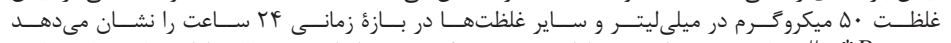

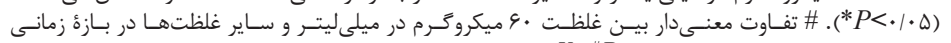

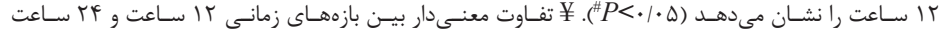

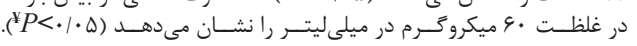

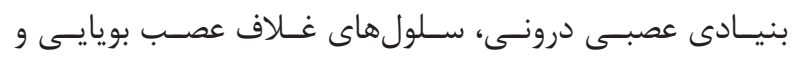

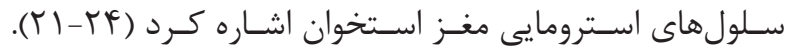



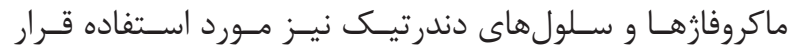

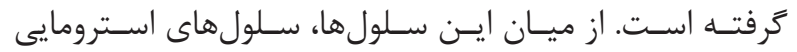

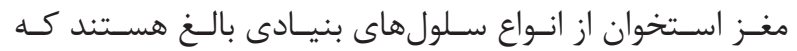

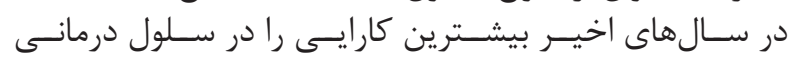

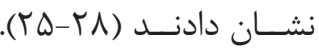

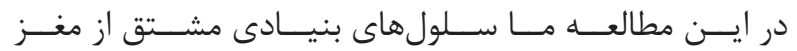

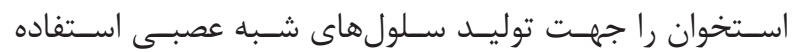

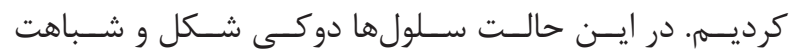

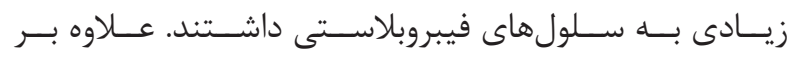

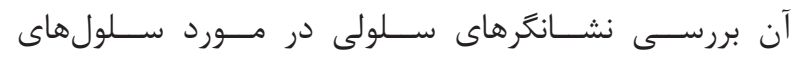

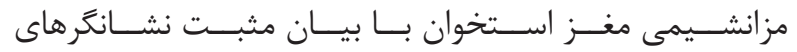

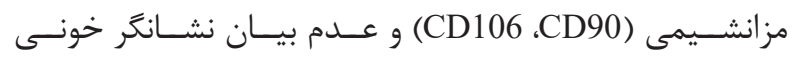

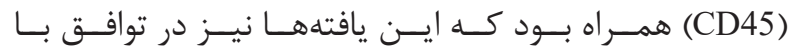



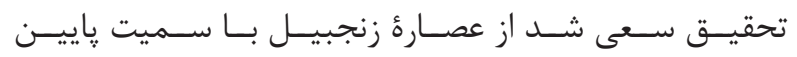

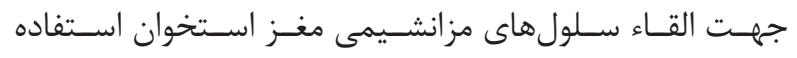

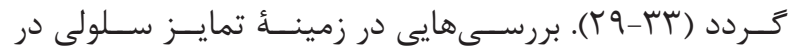





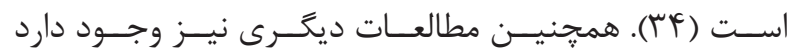

بحث و نتيجهَ



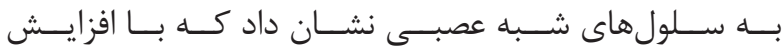

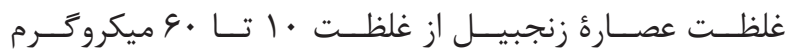

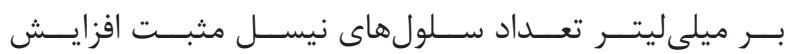

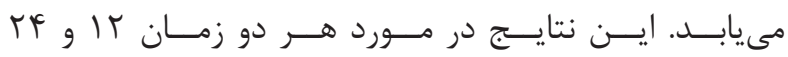

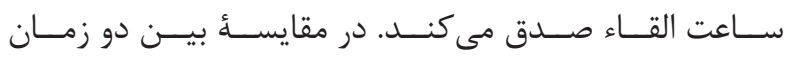

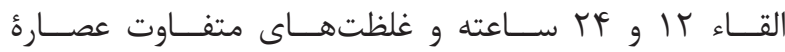

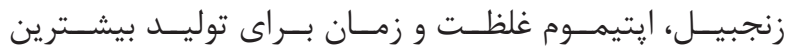

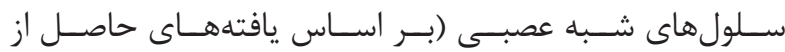

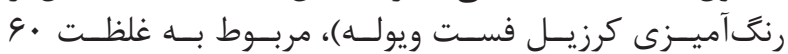

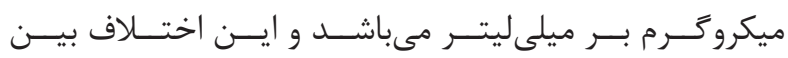

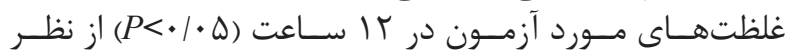

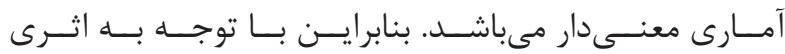

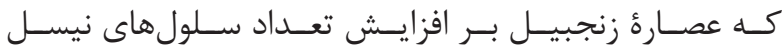

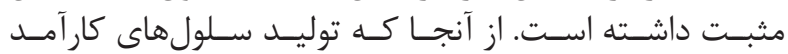

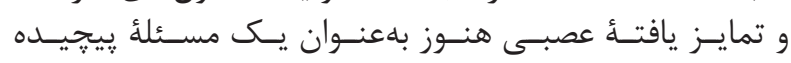

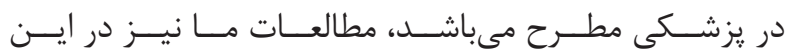

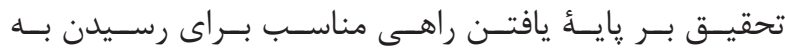

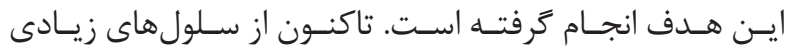

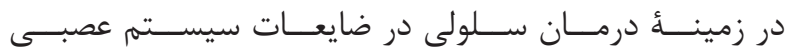

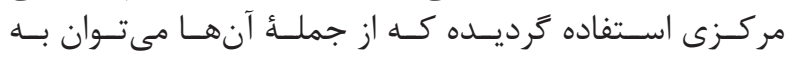

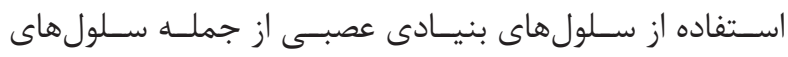




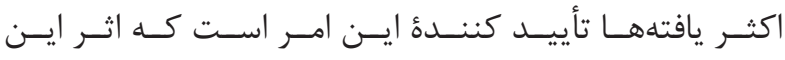

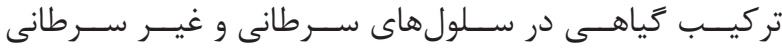



در بررسـى كـهـ توسـط سـاير محققيــن انجـام شـــ نشـان داد

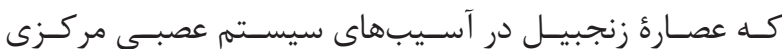

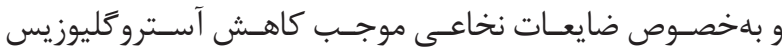

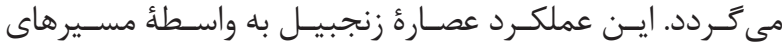

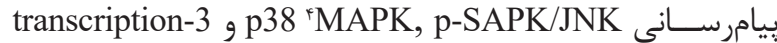
رخ مى دهـــ activation

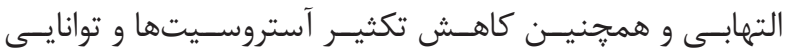



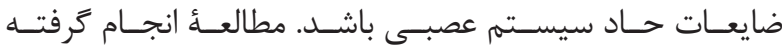

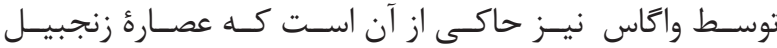

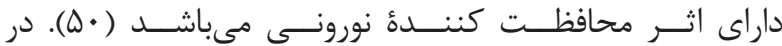

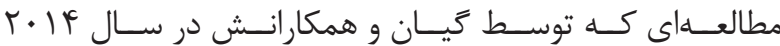

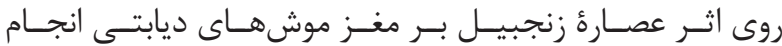



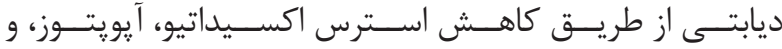

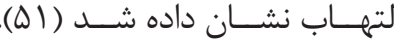

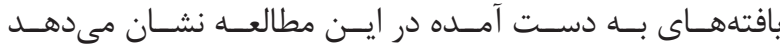

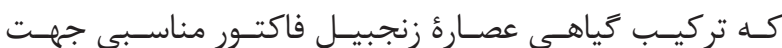

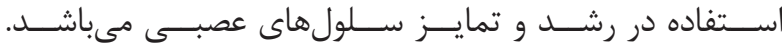

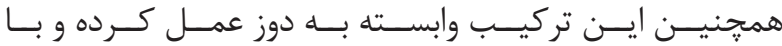

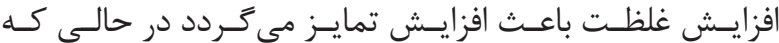

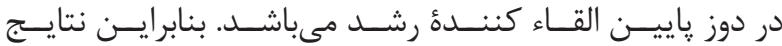

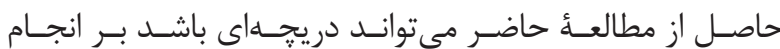

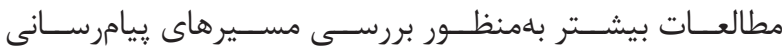



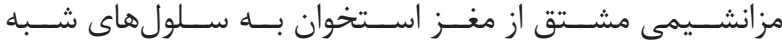

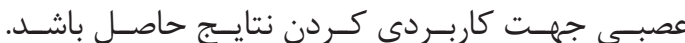

1. Ide C, Kitada M, Chakrabortty S, Taketomi M, Matsumoto N, kikokama S, et al. Grafting of choroid plexus ependymal cells promotes the growth of regenerating axons in the dorsal funiculus of rat spinal cord: a preliminary report. Exp Neurol. 2001; 167(2): 242-51.

2. Sasaki M, Honmou O, Akiyama Y, Uede T, Hashi K, Koesis JD, et al. Transplantation of an acutely isolated bone marrow fraction repairs demyelinated adult rat spinal cord axons. Glia. 2001; 35(1): 26-34.

3. Lee J, Kuroda S, Shichinohe H, Ikeda J, Seki TH Migration and differentiation of nuclear fluorescencelabeled bone marrow stromal cells after transplanrtation into cerebral infarct and spinal cord injury in mice. Neuropathology. 2003; 23(3): 169-80.



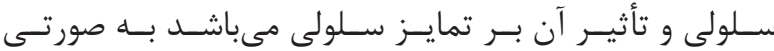

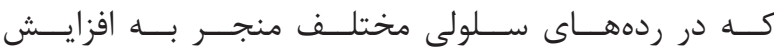

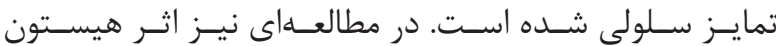

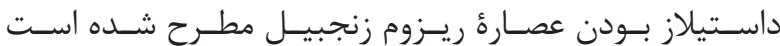

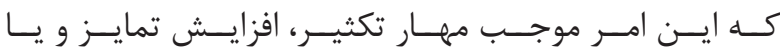

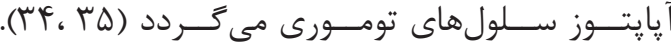



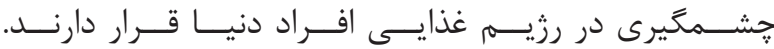

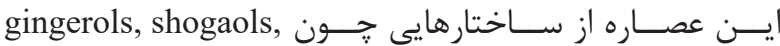
gingerdiones



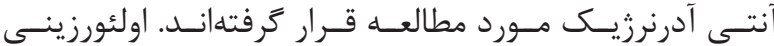

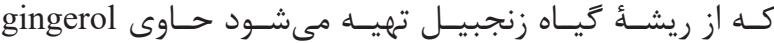

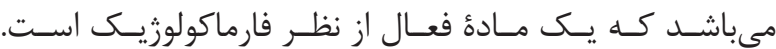

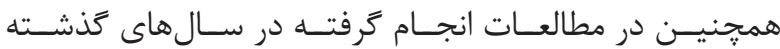

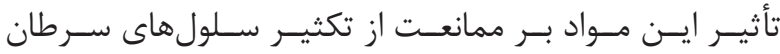

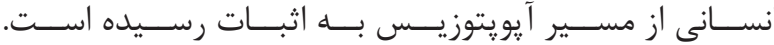

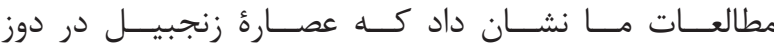

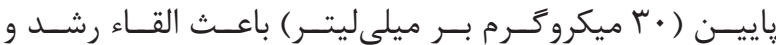

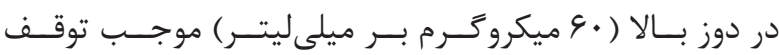

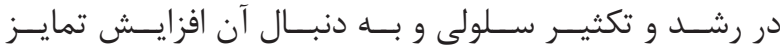

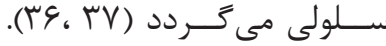

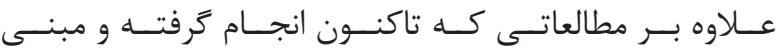

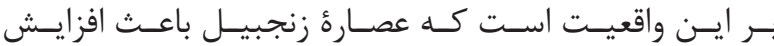

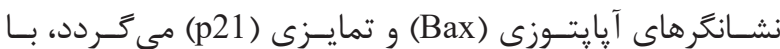

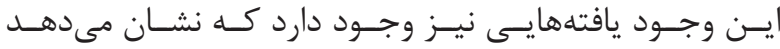

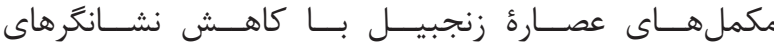

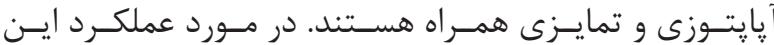

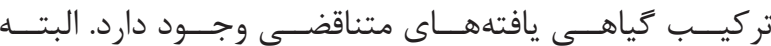

\section{منابع}

4. Zurita M, Vaquero J. Functional recovery in chronic paraplegia after bone marrow stromal cells transplantation. Neuroreport. 2004; 15(7): 1105-8.

5. Ankeny DP, Mctigue DM, Jakeman LB. Bone marrow transplants provide tissue protection and directional guidence for axons after contusive spinal cord injury in rats. Exp Neurology. 2004; 190(1): 17-31.

6. Garcia R, Aguiar J. Bone marrow stromal cells produce nerve growth factor and glial cell line derived neurotrophic factor. J Biochem Brain Res. 2004; 316(3): 753-4.

7. Jiang Y, Henderson D. Neuroectodermal differentiation from mouse multipotent adult progenitor cells. Proc Nat Acad Sci USA. 2003; 100: 11854-60.

${ }^{4}$ Mitogen-activated protein kinase 
8. Jiang Y, Jahagirdar BN. Pleuripotency of mesenchymal stem cells derived from adult marrow. Nature. 2002; 418 (6893): 41-9.

9. Bodega G, Suarez I, Rubio M, B Fernandez. Ependyma: phylogenetic evolution of glial fibrillary acidic protein (GFAP) and vimentin expression in vertebrate spinal cord. Histochemistry. 1994; 102(2): 113-2.

10. Waggas AM. "Neuroprotective evaluation of extract of ginger (Zingiber officinale) root in monosodium glutamateinduced toxicity in different brain areas male albino rats". Pakistan Journal of Biological Sciences. 2009; 12(3): 201-12.

11. Asnani V, Verma RJ. "Antioxidative effect of rhizome of Zingiber officinale on paraben induced lipid peroxidation: an in vitro study". Acta Poloniae Pharmaceutica. 2007; 64(1): 35-7.

12. Oliveira $\mathrm{CH}$, Moraes MEA, Moraes MO, Bezerra FAF, Abib E, De Nucci G. "Clinical toxicology study of an herbal medicinal extract of Paullinia cupana, Trichilia catigua, Ptychopetalum olacoides and Zingiber officinale (Catuama_) in healthy volunteers". Phytotherapy Research. 2005; 19(1): 54-7.

13. PM Wiedemann, J Simon, S Schicktanz, C Tannert. The future of stem-cell research in Germany. EMBO Reports. 2004; 5(10): 927-31.

14. Robey PG. Stem cells near the century mark. J Clin Invest. 2000; 105(11): 1489-91.

15. Wiessman IL. Stem cells: units of development, units of regeneration and units of evolution. Cell. 2000; 100(1): 157-68.

16. Adib S, Tiraihi T, Darvishi M, Taheri T, Kazemi H. Cholinergic differentiation of neural stem cells generated from cell aggregates-derived from human bone marrow stromal cells. Tissue Engineering and Regenerative Medicine. 2015; 12(1): 43-52.

17. Evaluating the function of motoneuron -like cells differentiated from rat adipose derived stem cells through Calcium ion imaging and investigating the synaptic vesicle recycling. Iranian Biomedical Journal. 2013; 18(5): 254-66.

18. barati P, Darvishi M, Tiraihi T, Doroudi T. Neurogenic differentiation of rat bone marrow stromal cells by non toxic factors of bioactive substance as inducer. Shefaye Khatam. 2014; 2(2): 47-55.

19. Alfaro M, Bélanger J, Padilla J, Paré J. Influence of solvent, matrix dielectric properties, and applied power on the liquid-phase microwave-assisted processes
(MAPTM)1 extraction of ginger (Zingiber officinale). Food Research International. 2003; 36(5): 499-504.

20. Darvishi M, Tiraihi T, Mesbah-Namin SA, Delshad A, Taheri T. Motor neuron transdifferentiation of neural stem cell from adipose-derived stem cell characterized by differential gene expression. Cell Mol Neurobiol. 2016. doi: 10.1007/s10571-016-0368-x.

21. Bianco P, Riminucci M, Gronthos S, Roby PG. Bone marrow stromal cells, nature,biology and potential applications. Stem Cells. 2001; 19(3): 180-92.

22. Aeschbach R, Loliger J, Scott BC, Murcia A, Butler J, Halliwell B, et al. Antioxidant actions of thymol, carvacrol, [6]-gingerol, zingerone and hydroxytyrosol. Food Chem Toxicol. 1994; 32(1): 31-6.

23. Aktan F, Henness S, Tran VH, Duke CC, Roufogalis BD, Ammit AJ. Gingerol metabolite and a synthetic analogue Capsarol inhibit macrophage NF-kappaBmediated iNOS gene expression and enzyme activity. Planta Med. 2006; 72(8): 727-34.

24. Ali BH, Blunden G, Tanira MO, Nemmar A. Some phytochemical, pharmacological and toxicological properties of ginger (Zingiber officinale Roscoe): a review of recent research. Food Chem Toxicol. 2008; 46(2): 409-20.

25. Alizadeh-Navaei R, Roozbeh F, Saravi M, Pouramir M, Jalali F, Moghadamnia A. Investigation of the effect of ginger on the lipid levels. A double blind controlled clinical trial. Saudi Med J. 2008; 29(9): 1280-4.

26. Altman R D, Marcussen KC. Effects of a ginger extract on knee pain in patients with osteoarthritis. Arthritis Rheum. 2001; 44(11): 2531-8.

27. Antipenko AY, Spielman AI, Kirchberger MA. Interactions of [6]-gingerol and ellagic acid with the cardiac sarcoplasmic reticulum Ca2+-AT Pase. J Pharmacol Exp Ther. 1999; 290(1): 227-34.

28. Bhandari U, Sharma JN, Zafar R. The protective action of ethanolic ginger (Zingiber officinale) extract in cholesterol fed rabbits. J Ethnopharmacol. 1998; 61(2): 167-71.

29. Bode AM, Ma WY, Surh Y J, Dong Z. Inhibition of epidermal growth factor-induced cell trans-formation and activator protein 1 activation by [6]-gingerol. Cancer Res. 2001; 61(3): 850-3.

30. Brown AC, Shah C, Liu J, Pham JT, Zhang JG, Jadus MR. Ginger's (Zingiber officinale Roscoe) inhibition of rat colonic adenocarcinoma cellsproliferation and angiogenesis in vitro. Phytother Res. 2009; 23(5): 640-5. 
31. Buddhakala N, Talubmook C, Sriyotha P, Wray S, Kupittayanant S. Inhibitory effects of ginger oil on spontaneous and PGF2alpha-induced contraction of rat myometrium. Planta Med. 2008; 74(4): 385-91.

32. Chen CY, Liu TZ, Liu YW, Tseng WC, Liu R, Lu FJ, et al. 6 -shogaol (alkanone from ginger) induces apoptotic cell death of human hepatoma p53 mutant Mahlavu subline via an oxidative stress-mediated caspase-dependent mechanism. J Agric Food Chem. 2007; 55(3): 948-54.

33. Chung M, Kim MY, Park WH, Moon HI. Histone deacetylase inhibitors from the rhizomes of Zingiber zerumbet. Pharmazie. 2008; 63: 774-6.

34. Sekiya K, Ohtani A, Kusano S. Enhancement of insulin sensitivity in adipocytes by ginger. Biofactors. 2004; 22(1-4): 153-6.

35. Kuroyanagi M, Umehara K, Hayashi T, Hirayamac Y. Cell differentiation inducers and antiandrogenic active compounds from zingiberis rhizoma. Natural Medicines. 2002; 56(2): 47-50.

36. Creson TK, Yuan P, Manji HK, Chen G. Evidence for involvement of ERK, PI3K, and RSK in induction of Bcl2 by valproate. J Mol Neurosci. 2009; 37(2): 123-34.

37. Ernfors P, Lee KF, Jaenisch R. Mice lacking brainderived neurotrophic factor develop with sensory deficits. Nature. 1994; 368(6467): 147-50.

38. Grondin R, Gash DM. Glial cell line-derived neurotrophic factor (GDNF): a drug candidate for the treatment of Parkinson's disease. J Neurol. 1998; 11(3): $35-42$.

39. Hisaoka K, Takebayashi M, Tsuchioka M, Maeda N, Nakata Y, Yamawaki S. Antidepressants increase glial cell line-derived neurotrophic factor production through monoamine-independent activation of protein tyrosine kinase and extracellular signal-regulated kinase in glial cells. J Pharmacol Exp Ther. 2007; 321(1): 148-57.

40. Kim SD, Moon CK, Eun SY, Ryu PD, Jo SA. Identification of ASK1, MKK4, JNK, c-Jun, and caspase- 3 as a signaling cascade involved in cadmiuminduced neuronal cell apoptosis. Biochem Biophys Res Commun. 2005; 328(1): 326-34.

41. Klein R, Smeyne RJ, Wurst W, Long L K, Auerbach
BA, L Joyner A, et al. Targeted disruption of the trkB neurotrophin receptor gene results in nervous system lesions and neonatal death. Cell. 1993; 75(1): 113-22.

42. Lantz RC, Chen GJ, Sarihan M, Solyom AM, Jolad SD, Timmermann BN. The effect of extracts from ginger rhizome on inflammatory mediator production. Phytomedicine. 2007; 14(2-3): 123-8.

43. Liu YZ, Boxer LM, Latchman DS. Activation of the $\mathrm{Bcl}-2$ promoter by nerve growth factor is mediated by the p42/p44 MAPK cascade. Nucleic Acids Res. 1999; 27(10): 2086-90.

44. Masuda Y, Kikuzaki H, Hisamoto M, Nakatani N. Antioxidant properties of gingerol related compounds from ginger. Biofactors. 2004; 21(1-4): 293-6.

45. McCarthy KD, de Vellis J. Preparation of separate astroglial and oligodendroglial cell cultures from rat cerebral tissue. J Cell Biol. 1980; 85(3): 890-902.

46. Rudolph JG, Lemasters JJ, Crews FT. Effects of NMDA and ferrous sulfate on oxidation and cell death in primary neuronal cultures. Neurochem Int. 2000; 37(5-6): 497-507.

47. Scharfman H, Goodman J, Macleod A, Phani S, Antonelli C, Croll S. Increased neurogenesis and the ectopic granule cells after intrahippocampal BDNF infusion in adult rats. Exp Neurol. 2005; 192(2): 348-56.

48. Shim S, Kim S, Choi DS, Kwon YB, Kwon J. Antiinflammatory effects of [6]-shogaol: potential roles of HDAC inhibition and HSP70 induction. Food Chem Toxicol. 2011; 49(11): 2734-40.

49. Shim S, Kim S, Kwon YB, Kwon J. Protection by [6]-shogaol against lipopolysaccharide-induced toxicity in murine astrocytes is related to production of brainderived neurotrophic factor. Food Chem Toxicol. 2012; 50(3-4): 597-602.

50. Waggas, Abeer M. "Neuroprotective evaluation of extract of Ginger (Zingiber officinale) root in monosodium glutamate-induced toxicity in defferent brain areas male albino rats." Pakistan Journal of Biological Sciences. 2009; 12(3): 201-12.

51. El-Akabawy G, El-Kholy W. Neuroprotective effect of ginger in the brain of streptozotocin-induced diabetic rats. Ann Anat. 2014; 196(2-3): 119-28. 